\title{
Synthesis and Properties of Novel Fluorinated Polyamides Based on Noncoplanar Sulfoxide Containing Aromatic Bis(ether amine)
}

\author{
By Abbas SHOCKRAVI, ${ }^{1, *}$ Ebrahim ABOUZARI-LOTF, ${ }^{1,2}$ Ali JAVADI, ${ }^{1}$ and Salman TAHERI ${ }^{3}$
}

\begin{abstract}
A novel sulfoxide containing bis(ether amine) monomer, 2,2'-sulfoxide-bis[4-methyl(2-trifluoromethyl)4-aminophenoxy) phenyl ether] (M2), was synthesized from the halogen displacement of 2-chloro-5-nitrobenzotrifluoride with dibenzosulfoxide (DH) in the presence of potassium carbonate, followed by catalytic reduction of bis(ether nitro) intermediate with Zinc/Ammonium chloride. A series of organic-soluble poly(ether amide)s (PA1-7) bearing sulfoxide and electronwithdrawing trifluoromethyl group were synthesized from bis(ether amine) with various aromatic diacids (1-7) via a direct polycondensation with triphenyl phosphite and pyridine. The resulting polymers had inherent viscosities ranging from 0.35 to $0.90 \mathrm{dL} \mathrm{g}^{-1}$ at a concentration of $0.5 \mathrm{~g} / \mathrm{dL}$ in $\mathrm{N}, \mathrm{N}$-dimethylacetamide (DMAc) solvent at $25^{\circ} \mathrm{C}$. All the polymers showed outstanding solubility and could be easily dissolved in amide-type polar aprotic solvents (e.g., $N$-methyl-2-pyrrolidone (NMP), DMAc, and N,N-dimethylformamide) and even dissolved in less polar solvents (e.g., pyridine, and tetrahydrofuran). Also these polymers could be cast into flexible and tough films from DMAc solutions. The glass-transition temperatures of these poly(sulfoxide ether amide)s were recorded between $160-220^{\circ} \mathrm{C} .10 \%$ weight loss temperatures were recorded in the range of $400-505^{\circ} \mathrm{C}$ in nitrogen and $380-480{ }^{\circ} \mathrm{C}$ in air atmosphere.

KEY WORDS: Fluorinated Polyamides / Sulfoxide Containing Polyamide / Improved Solubility / Thermal Stability /
\end{abstract}

Wholly aromatic polyamides (PAs) have been noted for their excellent balance of thermal and mechanical properties, which make them useful as high-performance materials for advanced technologies. ${ }^{1-4}$ However due to their limited solubility in organic solvents and high melting and glasstransition temperature they have difficulties in processing. Part of these problems is caused by strong intermolecular hydrogen bonds; in general, the hydrogen bonding capability of the amide linkages causes strong intermolecular forces which give rise to very high transition or melting temperatures of the polyamides. Thus, considerable research has been undertaken to identify new ways to circumvent these restrictions. To develop easily processable high performance polymers, modifications that increase the solubility while maintaining the thermal stability are of particular interest. One of the successful approaches to increase solubility and processability of polyamides is by the introduction of flexible bonds, ${ }^{5-9}$ unsymmetric and less symmetric such as meta- or ortho-linkages, ${ }^{10-12}$ alicyclic, ${ }^{13,14}$ and kinked structures. ${ }^{15}$

Another approach employed to increase the solubility of rigid-rod polyamide is by incorporation of the nonlinear moieties such as a bulky noncoplanar groups in the polymer backbone. ${ }^{16-19}$ It is well known that the incorporation of bulky $\mathrm{CF}_{3}$ into polymers backbone results in an enhanced solubility and optical transparency together with a lowered dielectric constant which is attributed to low polarizability of $\mathrm{C}-\mathrm{F}$ bond and the increase in free volume. ${ }^{20-23}$ Furthermore it seems that insertion of sulfoxide in the polymer structure enhances the processability, thermal resistance, and solubility of the final polymer. ${ }^{24-26}$ In a previous study, ${ }^{26}$ we reported two series of poly(ether amide)s based on sulfide and sulfoxide containing monomers. It was found that polymers with $\mathrm{S}=\mathrm{O}$ bond in the main chain had a better solubility and thermal stability than sulfide-containing polymers. This might be due to the flexibility of $\mathrm{S}=\mathrm{O}$ bond that disturbed the planarity of aromatic units to reduce the packing efficiency and the crystallinity. The $\mathrm{X}$-ray crystallography of monomers that we reported previously, confirmed the disturbed planarity. ${ }^{27}$ In a continuation of these studies, this work deals with the synthesis of a new family of fluorinated ortho-sulfoxide bridged poly(ether amide)s based on novel aromatic diamine. It was expected that the incorporation of both the ortho-sulfoxide unit and the bulky $\mathrm{CF}_{3}$ group in noncoplanar structure, would decrease polymer interchain interactions and generally disturb the coplanarity of aromatic units to reduce packing efficiency and crystallinity. The general properties of the polymers such as crystallinity, thermal and physical properties will be described herein.

\section{EXPERIMENTAL}

\section{Materials}

The commercially available aromatic dicarboxylic acids such as terephthalic acid (1; Merck), isophthalic acid (2; Merck), pyridine 2,6-dicarboxylic acid (3; Merck), pyridine 2,5-dicarboxylic acid (4; Merck), pyridine 3,5-dicarboxylic

\footnotetext{
${ }^{1}$ Faculty of Chemistry, Tarbiat Moallem University, Mofatteh Ave. No. 49, Postal Code, 15614, Tehran, Iran

${ }^{2}$ Young Researcher Club of Iran

${ }^{3}$ Department of Chemistry, Sharif University of Technology, P.O. Box 11115-9516, Tehran, Iran

*To whom correspondence should be addressed (Tel: +98-21-88848946, Fax: +98-21-88825580, E-mail: Shockravi@tmu.ac.ir, Abbas_Shockravi@yahoo.co.uk).
} 
acid (5; Merck), 4,4'-oxydibenzoic acid (6; Aldrich) and 4,4'biphenyldicarboxylic acid (7; Aldrich) were used as received. 2-2'-sulfoxide-bis(4-methyl phenol) was synthesized from $p$ cresol as reported in literature, ${ }^{28}$ and recrystallized from ethanol. $N$-Methyl-2-pyrrolidone (NMP, Merck) and pyridine (Py, Fluka) were purified by distillation under reduced pressure over calcium hydride prior to use and stored over $4 \mathrm{~A}^{\circ}$ molecular sieves. Methanol was dried over calcium hydride before use. Triphenyl phosphite (TPP, Merck) was used without previous purification. $\mathrm{LiCl}$ (Merck) was dried for $10 \mathrm{~h}$. at $180^{\circ} \mathrm{C}$ under vacuum. 2-chloro-5-nitrobenzotrifluoride (Acros) was used as received.

\section{Instruments}

Elemental analysis was performed by a Perkin Elmer 2004 (II) $\mathrm{CHN}$ analyzer. IR spectra were recorded on a Perkin Elmer RX1 Fourier transform infrared spectrometer. ${ }^{1} \mathrm{H}$ and ${ }^{13} \mathrm{C}$ NMR spectra were measured on a Bruker DRX 500 AVANCE apparatus at 500 and $125 \mathrm{MHz}$ frequencies, respectively. Melting points (uncorrected) were measured with an Electrothermal engineering LTD 9200 apparatus. Inherent viscosities $\left(\eta_{\text {inh }}=\ln \eta_{\mathrm{r}} / \mathrm{c}\right.$ at a concentration of $\left.0.5 \mathrm{~g} \mathrm{dL}^{-1}\right)$ were measured with an Ubbelohed suspended-level viscometer at $30^{\circ} \mathrm{C}$ using $N, N$-dimethylacetamide (DMAc) as a solvent. Wide-angle X-ray diffraction (WAXD) measurements were performed at room temperature on a PW 1800 diffractometer (Philips) with graphite monochromatized $\mathrm{Cu} \mathrm{K} \alpha$ radiation $(\lambda=1.5401 \AA)$. The scanning rate was $0.08^{\circ} / \mathrm{s}$ over a range of $2 \theta=4-80^{\circ}$. Thermogravimetric analyses (TGA) were conducted with a Du Pont 2000 thermal analysis under nitrogen and air atmosphere at a heating rate of $10{ }^{\circ} \mathrm{C} \mathrm{min}^{-1}$. Glass-transition temperatures, taken as the midpoint of the change in slope of baseline, were measured on a 2010 DSC TA instrument with a heating rate of $10{ }^{\circ} \mathrm{C} \mathrm{min}^{-1}$. Refractive index was measured by a prism coupler Metricon 2000 at room temperature in open air. The measurements were made at a wavelength of $1320 \mathrm{~nm}$. Using linearly-polarized laser light with parallel (TE, transverse electric) and perpendicular (TM, transverse magnetic) polarization to the film plane, the inplane $\left(n_{\mathrm{TE}}\right)$ and out-of-plane $\left(n_{\mathrm{TM}}\right)$ refractive indices of the samples were determined.

\section{Preparation of 2,2'-Sulfoxide-bis[4-methyl(2-trifluorometh- yl)4-nitrophenoxy) phenyl ether] (M1)}

To a solution of 2-2'-sulfoxide-bis(4-methyl phenol) (10 mmol, $2.62 \mathrm{~g}$ ), $\mathrm{K}_{2} \mathrm{CO}_{3}(22 \mathrm{mmol}, 3.04 \mathrm{~g}$ ) in dimethylsulfoxide (DMSO) $(70 \mathrm{~mL})$, was added 2-chloro-5-nitrobenzotrifluoride ( $20 \mathrm{mmol}, 4.51 \mathrm{~g}$ ). It was heated at $90^{\circ} \mathrm{C}$ for $14 \mathrm{~h}$. After cooling to room temperature, the reaction mixture was poured into $400 \mathrm{~mL}$ of water to gain a yellow solid, which was collected, washed with water repeatedly and dried in vacuum. Recrystallization from ethanol yielded the desired dinitro compound as yellow powders in $95 \%$ yield. m.p. $200-201^{\circ} \mathrm{C}$; IR (KBr) 3110, 2954, 2886, 1639, 1603, 1548, 1488, 1365, 1344, 1267, 1208, 1130, 1088, 1061, 917, 839, 801, $679 \mathrm{~cm}^{-1} ;{ }^{1} \mathrm{H}$ NMR $\left(500 \mathrm{MHz}, \mathrm{CDCl}_{3}\right) ; \delta 2.30(\mathrm{~s}, 6 \mathrm{H}), 6.84-6.87 \quad(\mathrm{~d}, 2 \mathrm{H}$, $J=15.3 \mathrm{~Hz}$ ), 7.04-7.06 (d, 2H, $J=13.8 \mathrm{~Hz}), 7.40-7.43$ (dd,
$2 \mathrm{H}, J=13.8,2.8 \mathrm{~Hz}), 7.65(\mathrm{~s}, 2 \mathrm{H}), 8.31-8.34(\mathrm{dd}, 2 \mathrm{H}, J=$ $15.3,4.5 \mathrm{~Hz}), 8.52-8.53(\mathrm{~d}, 2 \mathrm{H}, J=4.5 \mathrm{~Hz}) \mathrm{ppm} ;{ }^{13} \mathrm{C} \mathrm{NMR}$ $\left(125 \mathrm{MHz}, \mathrm{CDCl}_{3}\right) ; \delta 160.37,150.20,141.57,137.32,134.11$, $130.59,128.52,126.22,123.35,123.05,120.90$ (quartet, ${ }^{1} J_{\mathrm{C}-\mathrm{F}}=271.65 \mathrm{~Hz}$ ), 120.15 (quartet, ${ }^{2} J_{\mathrm{C}-\mathrm{F}}=33.75$ ), 116.04 , 20.76 ppm; Anal. Calcd for $\mathrm{C}_{28} \mathrm{H}_{18} \mathrm{~F}_{6} \mathrm{~N}_{2} \mathrm{O}_{7} \mathrm{~S}: \mathrm{C}, 52.51 \%$; $\mathrm{H}$, $2.83 \%$; N, $4.37 \%$. Found C, 52.22\%; H, 2.94\%; N, $4.23 \%$.

Preparation of 2,2'-Sulfoxide-bis[4-methyl(2-trifluoromethyl)4-aminophenoxy) phenyl ether] (M2)

A suspension of the dinitro intermediate (M1) $(7 \mathrm{mmol}$, $4.48 \mathrm{~g})$ in $100 \mathrm{~mL}$ of dry methanol containing $\mathrm{Zn}(28 \mathrm{mmol}$, $1.8 \mathrm{~g}$ ) and ammonium chloride $(30 \mathrm{mmol}, 1.6 \mathrm{~g})$ was heated to a reflux temperature for $14 \mathrm{~h}$. The reaction mixture filtered through celite to remove the catalyst, and the filtrate was poured into $500 \mathrm{~mL}$ water. The white precipitate was filtered, dried and recrystallized from ethanol to afford a white powder diamine compound (90\% yield); m.p. $115-116^{\circ} \mathrm{C}$; IR (KBr) 3459, 3349, 3029, 2932, 1632, 1501, 1483, 1451, 1343, 1275, 1232, 1212, 1130, 1046, $833 \mathrm{~cm}^{-1}$; ${ }^{1} \mathrm{H}$ NMR $(500 \mathrm{MHz}$, $\left.\mathrm{CDCl}_{3}\right) ; \delta 2.30(\mathrm{~s}, 6 \mathrm{H}), 6.31-6.34(\mathrm{~d}, 2 \mathrm{H}, J=14.6 \mathrm{~Hz}), 6.55$ $6.58(\mathrm{~d}, 2 \mathrm{H}, J=14 \mathrm{~Hz}), 6.66-6.69(\mathrm{dd}, 2 \mathrm{H}, J=14.6,4.5 \mathrm{~Hz})$, 6.97-6.98 (d, 2H, $J=4.5 \mathrm{~Hz}), 7.23-7.26(\mathrm{dd}, 2 \mathrm{H}, J=14$, $2.8 \mathrm{~Hz}), 7.50-7.51(\mathrm{~d}, 2 \mathrm{H}, J=2.8 \mathrm{~Hz}) \mathrm{ppm} ;{ }^{13} \mathrm{C} \mathrm{NMR}(125$ $\left.\mathrm{MHz}, \mathrm{CDCl}_{3}\right) ; \delta 153.76,145.15,143.62,133.41,133.31$, $133.00,131.74,129.00,123.55$ (quartet, ${ }^{1} J_{\mathrm{C}-\mathrm{F}}=270.25 \mathrm{~Hz}$ ), 124.68, 121.55 (quartet, ${ }^{2} J_{\mathrm{C}-\mathrm{F}}=33.45$ ), $117.58,113.84,19.21$ ppm; Anal. Calcd for $\mathrm{C}_{28} \mathrm{H}_{22} \mathrm{~F}_{6} \mathrm{~N}_{2} \mathrm{O}_{3} \mathrm{~S}$ : C, 57.93\%; H, 3.82\%; $\mathrm{N}, 4.83 \%$. Found C, 57.69\%; H, 3.76\%; N, 4.68\%.

\section{Polymer Synthesis}

The polymer synthesis was carried out in a $10 \mathrm{~mL}$ three necked round bottom flask, equipped with a magnetic stirrer under nitrogen atmosphere, following the general phosphorylation polycondensation procedure. ${ }^{29}$ A typical example for the preparation of polyamides is given. Polyamide PA-1 was synthesized from diamine and diacid 1. A mixture of $0.580 \mathrm{~g}$ ( $1 \mathrm{mmol})$ of diamine, $0.166 \mathrm{~g}(1 \mathrm{mmol})$ of diacid $1,0.3 \mathrm{~g}$ of $\mathrm{LiCl}, 0.6 \mathrm{~mL}$ of TPP, $0.5 \mathrm{~mL}$ of pyridine, and $2.5 \mathrm{~mL}$ of NMP was heated and stirred at $130{ }^{\circ} \mathrm{C}$ for $6 \mathrm{~h}$, under nitrogen atmosphere. The resulting reaction mixture was poured into $300 \mathrm{~mL}$ of methanol. This stringy polymer was washed thoroughly with methanol and hot water, collected by filtration and dried under vacuum at $100{ }^{\circ} \mathrm{C}$ overnight. The yield was almost quantitative. The inherent viscosity was $0.90 \mathrm{dL} \mathrm{g}^{-1}$, measured at a concentration of $0.5 \mathrm{~g} \mathrm{dL}^{-1}$ in DMAc at $30^{\circ} \mathrm{C}$. The absorption bands were observed at $3295 \mathrm{~cm}^{-1}(\mathrm{~N}-\mathrm{H}$ stretch), $1420 \mathrm{~cm}^{-1}$ (N-H bending), $1666 \mathrm{~cm}^{-1}(\mathrm{C}=\mathrm{O})$, phenyl alkyl ether 1048 and $1258 \mathrm{~cm}^{-1}$ in IR spectrum. Anal. Calcd for $\mathrm{C}_{36} \mathrm{H}_{24} \mathrm{~F}_{6} \mathrm{~N}_{2} \mathrm{O}_{5} \mathrm{~S}$ : C, 60.84\%; H, 3.40\%; N, 3.94\%. Found C, $60.45 \%$; H, 3.52\%; N, 3.69\%.

\section{RESULTS AND DISCUSSION}

\section{Monomer Synthesis}

2,2'-Sulfoxide-bis[4-methyl(2-trifluoromethyl)4-nitrophen- 
<smiles>Cc1ccc(O)c(S(=O)c2cc(C)ccc2O)c1</smiles>

DH<smiles>Cc1ccc(Oc2ccc([N+](=O)[O-])cc2C(F)(F)F)c(S(=O)c2cc(C)ccc2Oc2ccc([N+](=O)[O-])cc2C(F)(F)F)c1</smiles>

M1

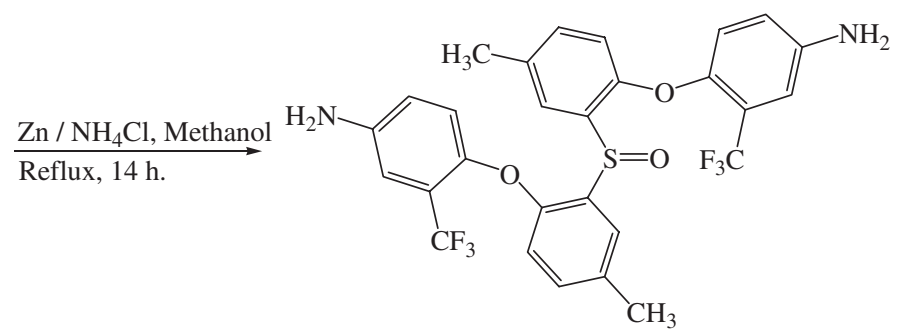

M2

Figure 1. Synthesis of diamine monomer.<smiles>Cc1ccc(Oc2ccc(C)cc2C(F)(F)F)c(C(=O)c2cc([N+](=O)[O-])ccc2Oc2ccc([N+](=O)[O-])cc2C(F)(F)F)c1</smiles><smiles>Cc1ccc(Oc2ccc(N)cc2C(F)(F)F)c(S(=O)c2cc(C)ccc2Oc2ccc(N)cc2C(F)(F)F)c1</smiles>
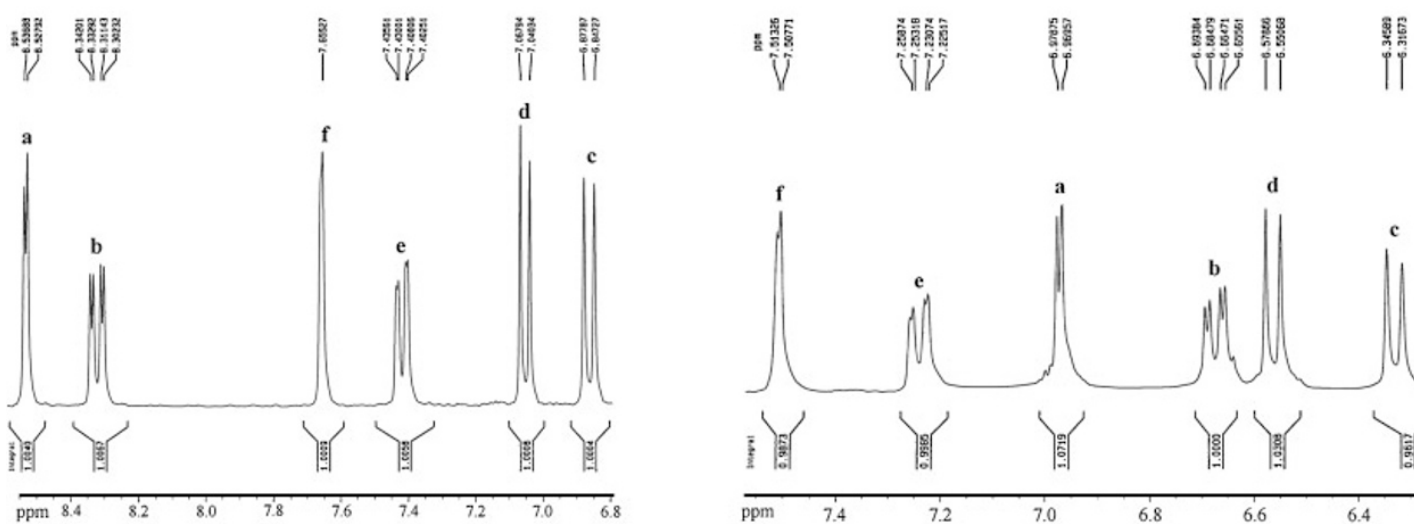

Figure 2. ${ }^{1} \mathrm{H}$ NMR spectra of sulfoxide bis(ether nitro) M1 and sulfoxide bis(ether amine) M2.

oxy) phenyl ether] (M1) was synthesized by nucleophilic aromatic substitution reaction of 2-2'-sulfoxide-bis(4-methyl phenol) with 2-chloro-5-nitrobenzotrifluoride using potassium carbonate as a base in DMSO. The fluorinated diamine monomer, 2,2'-sulfoxide-bis[4-methyl(2-trifluoromethyl)4aminophenoxy) phenyl ether] (M2) was prepared by the reduction of intermediate dinitro compound M1 with Zinc/ Ammonium chloride in refluxing methanol according to the synthetic route outlined in Figure 1.

IR spectroscopy was used to identify the structures of the
M1 and M2 monomers. The characteristic bands representative of the nitro functionality (asymmetrical stretch at $1550 \mathrm{~cm}^{-1}$ and the symmetrical stretch at $1365 \mathrm{~cm}^{-1}$ ) were disappeared after reduction, and the characteristic bands of aromatic primary amine absorptions at 3460 and $3350 \mathrm{~cm}^{-1}$ were identified. Figure 2 illustrates the ${ }^{1} \mathrm{H}$ NMR spectra of dinitro M1 and diamine M2 compounds. The assignments of each proton are also given in the figure, and these spectra agree well with the proposed structures. The ${ }^{1} \mathrm{H}$ NMR spectra confirm that the nitro groups were completely converted into amino groups 
<smiles>Cc1ccc(Oc2ccc(N)cc2C(F)(F)F)c(S(=O)c2cc(C)ccc2Oc2ccc(N)cc2C(F)(F)F)c1</smiles>

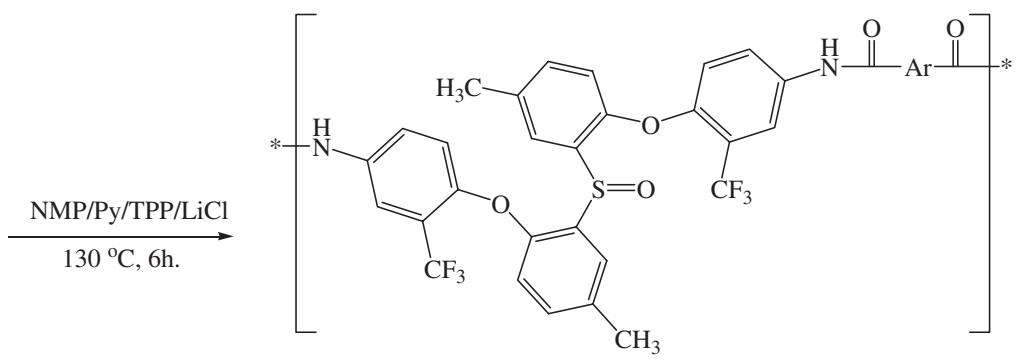

PA-1_PA-7

Ar: (1)<smiles>Cc1ccc(Cl)cc1</smiles>

(2)<smiles>Cc1cccc(I)c1</smiles>

(3)<smiles>Cc1cccc(C)n1</smiles>

(4)<smiles>Cc1ccc(C)nc1</smiles>

(5)<smiles>Cc1cncc(I)c1</smiles>
(6)<smiles>Cc1ccc(Oc2ccc(C)cc2)cc1</smiles><smiles>Cc1ccc(-c2ccc(Br)cc2)cc1</smiles>

Figure 3. Synthesis of polyamides.

Table I. Viscosities and solubility of polyamides

\begin{tabular}{|c|c|c|c|c|c|c|c|c|c|}
\hline \multirow{2}{*}{ Polymer } & \multirow{2}{*}{$\eta_{\text {inh }}(\mathrm{dL} / \mathrm{g})^{\mathrm{a}}$} & \multicolumn{8}{|c|}{ Solvent ${ }^{b}$} \\
\hline & & NMP & DMAC & DMF & DMSO & THF & Py & $m$-Cresol & Dioxane \\
\hline PA-1 & 0.90 & ++ & ++ & ++ & ++ & + & + & - & \pm \\
\hline PA-2 & 0.40 & ++ & ++ & ++ & ++ & + & ++ & \pm & + \\
\hline PA-3 & 0.35 & ++ & ++ & ++ & ++ & + & + & \pm & + \\
\hline PA-4 & 0.50 & ++ & ++ & ++ & ++ & + & + & $S$ & + \\
\hline PA-5 & 0.40 & ++ & ++ & ++ & ++ & ++ & ++ & \pm & ++ \\
\hline PA-6 & 0.73 & ++ & ++ & ++ & ++ & ++ & \pm & \pm & + \\
\hline PA-7 & 0.85 & ++ & ++ & ++ & ++ & + & + & - & - \\
\hline
\end{tabular}

$(++)$ Soluble at $10 \%(\mathrm{w} / \mathrm{v}),(+)$ soluble at $5 \%(\mathrm{w} / \mathrm{v}),( \pm)$ partial soluble on heating, $(\mathrm{S})$ swelling, $(-)$ insoluble on heating. ${ }^{a}$ Measured at a polymer concentration of $0.5 \mathrm{~g} / \mathrm{dl}$ in DMAc solvent at $25^{\circ} \mathrm{C}$. ${ }^{\mathrm{b}} \mathrm{NMP}: \mathrm{N}$-methyl-2-pyrrolidone; DMAc: $\mathrm{N}, \mathrm{N}$-dimethylacetamide; DMF: $\mathrm{N}, \mathrm{N}$-dimethylformamide; DMSO: dimethyl sulfoxide; THF: tetrahydrofuran; Py: Pyridine.

by the high field shift of the aromatic proton. In the ${ }^{13} \mathrm{C} N \mathrm{NR}$ spectra, upfield shifts of the aromatic carbon resonances, especially for the carbons para and ortho to the amino group, were observed in diamine $\mathbf{M} 2$ because of the resonance effect caused by the electron-donating amino group. Moreover, the results of elemental analysis obtained were in agreement with the expected structures.

\section{Polymer Synthesis}

Polyamides PA1-PA7 were prepared by Yamazaki's phosphorylation polyamidation technique that involved the direct polycondensation of diamine M2 and diacids 1-7 using triphenyl phosphite and pyridine as condensing agent in $\mathrm{NMP}$ containing $\mathrm{LiCl}$ at $130^{\circ} \mathrm{C}$ for $6 \mathrm{~h}$ (Figure 3). The direct polycondensation was used as it avoids tedious workup in preparation of diacid chloride and is an efficient way to obtain polyamides of moderate to high degree of polymerization. The PAs were obtained in 93-98\% yields and their inherent viscosity values ranged from 0.35 to $0.90 \mathrm{dL} / \mathrm{g}$ (Table I). Since, the inherent viscosity is a good criterion for estimation of molecular weight, the prepared polyamides showed reasonable molecular weights. The molecular weight of the polymers was high enough to obtain flexible and tough polymer films by casting from their NMP solutions. 
Table II. Elemental analysis of polymers

\begin{tabular}{|c|c|c|c|c|c|c|c|c|}
\hline \multicolumn{2}{|c|}{$\begin{array}{l}\text { Polymer } \\
\text { Formula }\end{array}$} & $\begin{array}{c}\text { PA-1 } \\
\mathrm{C}_{36} \mathrm{H}_{24} \mathrm{~F}_{6} \mathrm{~N}_{2} \mathrm{O}_{4} \mathrm{~S}\end{array}$ & $\begin{array}{c}\text { PA-2 } \\
\mathrm{C}_{36} \mathrm{H}_{24} \mathrm{~F}_{6} \mathrm{~N}_{2} \mathrm{O}_{4} \mathrm{~S}\end{array}$ & $\begin{array}{c}\text { PA-3 } \\
\mathrm{C}_{35} \mathrm{H}_{23} \mathrm{~F}_{6} \mathrm{~N}_{3} \mathrm{O}_{5} \mathrm{~S}\end{array}$ & $\begin{array}{c}\text { PA-4 } \\
\mathrm{C}_{35} \mathrm{H}_{23} \mathrm{~F}_{6} \mathrm{~N}_{3} \mathrm{O}_{5} \mathrm{~S}\end{array}$ & $\begin{array}{c}\text { PA-5 } \\
\mathrm{C}_{35} \mathrm{H}_{23} \mathrm{~F}_{6} \mathrm{~N}_{3} \mathrm{O}_{5} \mathrm{~S}\end{array}$ & $\begin{array}{c}\text { PA-6 } \\
\mathrm{C}_{42} \mathrm{H}_{28} \mathrm{~F}_{6} \mathrm{~N}_{2} \mathrm{O}_{6} \mathrm{~S}\end{array}$ & $\begin{array}{c}\text { PA-7 } \\
\mathrm{C}_{42} \mathrm{H}_{28} \mathrm{~F}_{6} \mathrm{~N}_{2} \mathrm{O}_{5} \mathrm{~S}\end{array}$ \\
\hline \multirow{6}{*}{ 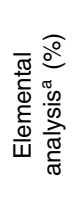 } & $\mathrm{C}$ & 60.45 & 60.51 & 59.29 & 59.32 & 59.38 & 62.70 & 64.35 \\
\hline & & $(60.84)$ & $(60.84)$ & (59.07) & (59.07) & (59.07) & (62.84) & (64.12) \\
\hline & $\mathrm{H}$ & 3.52 & 3.63 & 3.35 & 3.39 & 3.15 & 3.45 & 3.66 \\
\hline & & (3.40) & (3.40) & (3.26) & (3.26) & (3.26) & (3.52) & (3.59) \\
\hline & $\mathrm{N}$ & 3.69 & 3.74 & 5.75 & 5.68 & 5.78 & 3.60 & 3.43 \\
\hline & & (3.94) & (3.94) & (5.90) & $(5.90)$ & (5.90) & (3.49) & (3.56) \\
\hline
\end{tabular}

${ }^{a}$ Calculated values are reported in parentheses.

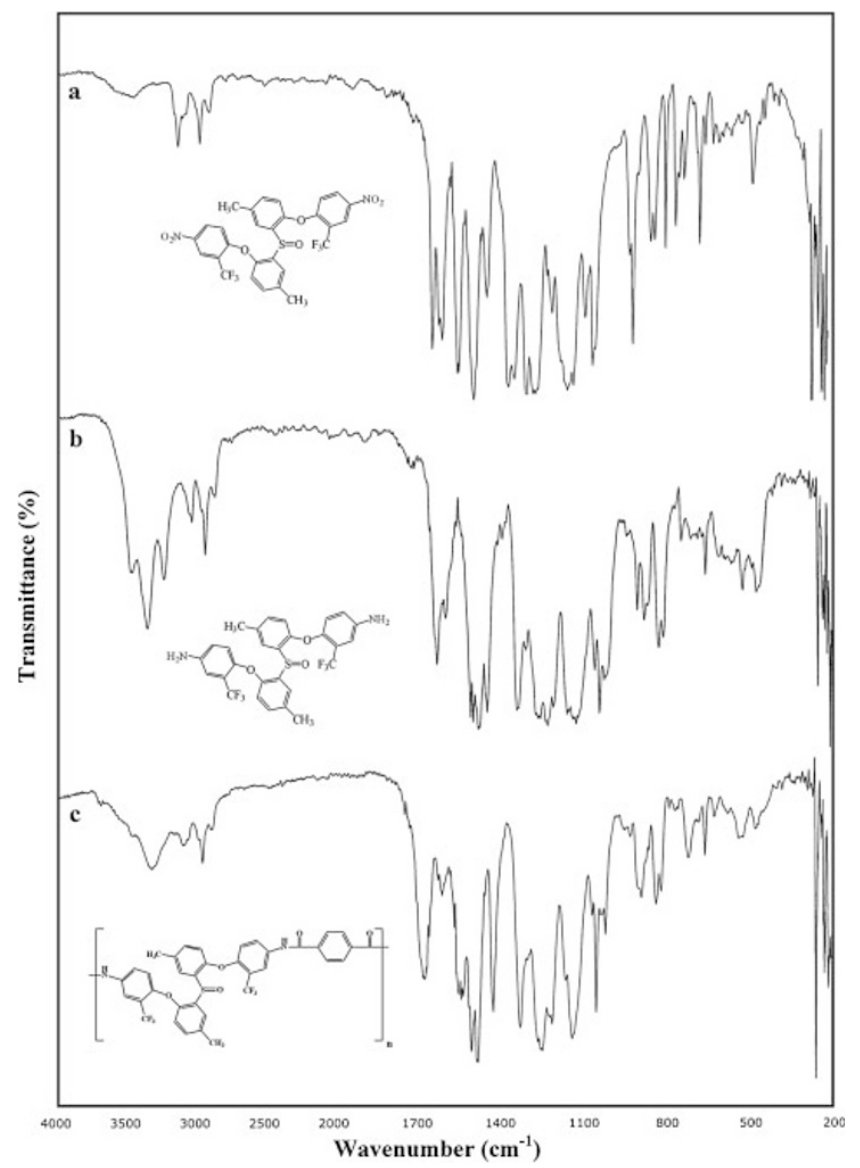

Figure 4. IR spectra of (a) sulfoxide bis(ether nitro) DN, (b) sulfoxide bis(ether amine) DA, and (c) polyamide PA-1.

The structural features of these polyamides were verified by IR and ${ }^{1} \mathrm{H}$ NMR spectroscopies, and a typical FT-IR spectrum of polyamide PA-1 is shown in Figure 4. The characteristic absorption bands of the amide group were observed around $3310 \mathrm{~cm}^{-1}$ (N-H stretch), $1430 \mathrm{~cm}^{-1}$ (N-H bending), and 1665 $\mathrm{cm}^{-1}(\mathrm{C}=\mathrm{O})$, aryl ether stretching near $1255 \mathrm{~cm}^{-1}$, and that of C-F stretching appeared around $1140 \mathrm{~cm}^{-1}$. ${ }^{1} \mathrm{H}$ NMR spectra of the polyamides showed amide groups (-NH) protons at the most downfield region, about (10.5) ppm, aromatic proton at the region of about (6.5-8.8) ppm, and aromatic methyl group at around (2.2) ppm. Also the results of elemental analysis shown in Table II supported the formation of the expected polymers.

\section{Polymer Properties}

The solubility of polyamides was studied qualitatively and the results are summarized in Table I. The table data show that all polymers were soluble at more than $10 \%(\mathrm{w} / \mathrm{v})$ in aprotic polar solvents such as NMP, DMAc and DMF. Except for PA-1 and PA-7, all the polyamides were soluble in moderate polar solvents such as THF, $m$-cresol and pyridine at room temperature or upon heating. As indicated in Table I, the solubility of the polyamides derived from dicardoxylic acids containing meta-catenated aromatic unit, such as PA-2, PA-3, and PA-5, revealed a higher solubility due to the interrupted the chain packing and decreased intermolecular interactions. The good solubility of these polyamides can be attributed to the effect of the large volume of $\mathrm{CF}_{3}$ groups and polarized $\mathrm{S}=\mathrm{O}$ bond, which disrupted regularity and dense chain packing leading to decreased interchain interactions. Comparison of the solubility of the previously reported sulfur containing analogues polymers ${ }^{30}$ with these sulfoxide containing polymers indicated that polyamides with sulfoxide group in main chain were more soluble in less polar solvents such as THF, $m$-cresol and pyridine. This might be due to the presence of the polarized $\mathrm{S}=\mathrm{O}$ bond which disturb the planarity of aromatic units to reduce the close packing and the crystallinity. The X-ray crystallography of monomers that we reported previously confirmed the disturbed planarity character. ${ }^{27}$

The crystallinity of all poly(sulfoxide ether amide)s was determined by wide-angle X-ray diffraction (WAXD) scans. Diffractograms indicated that all of the polymers were almost completely amorphous. It was related to the presence of the ortho sulfoxide linkage between two aromatic rings in diamine monomer and also pendant methyl and trifluoromethyl groups. The incorporation of less symmetric, such as ortho-catenated and pendant groups reduce the backbone symmetry and regularity, through weakening intermolecular hydrogen bonding, and a lowering chain packing efficiency which results in decreased crystallinity. A representative wide-angle X-ray diffractogram of the polymers is shown in Figure 5.

The refractive indices of polymer films were in the range of 1.5711 to $1.5941\left(n_{\mathrm{TE}}\right)$ and 1.5631 to $1.5805\left(n_{\mathrm{TM}}\right)$ (Table III). These low refractive indices were attributed to the small electronic polarizability and large free volume of the $\mathrm{C}-\mathrm{F}$ bonds.

The thermal properties of the polyamides were evaluated by thermogravimetry analysis (TGA) and differential scanning calorimetry (DSC). The thermal behavior data of all polymers 


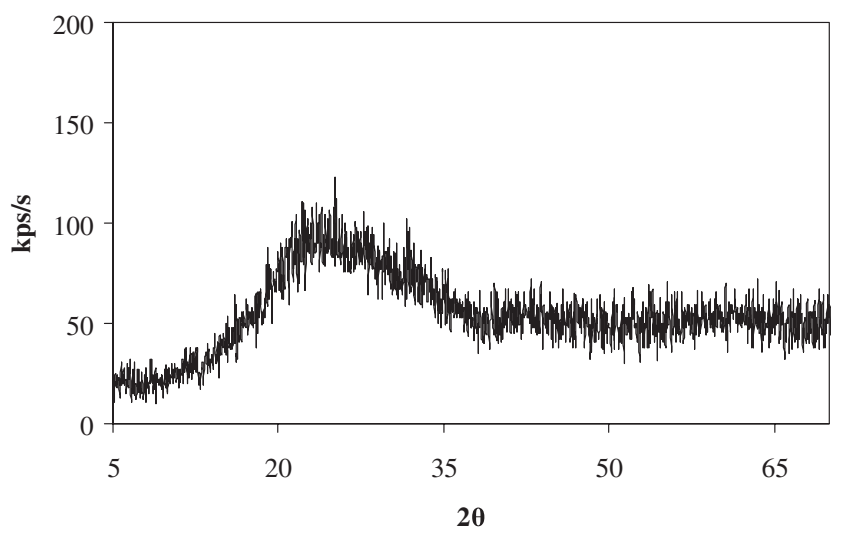

Figure 5. Wide-angle X-ray diffraction pattern of PA-1.

Table III. Refractive index of various polyamide films

\begin{tabular}{cccc}
\hline Polymer & $n_{\mathrm{TE}}$ & $n_{\mathrm{TM}}$ & $n_{\mathrm{AV}}{ }^{\mathrm{a}}$ \\
\hline PA-1 & 1.5870 & 1.5742 & 1.5827 \\
PA-2 & 1.5789 & 1.5671 & 1.5749 \\
PA-3 & 1.5711 & 1.5631 & 1.5684 \\
PA-4 & 1.5801 & 1.5713 & 1.5771 \\
PA-5 & 1.5723 & 1.5603 & 1.5683 \\
PA-6 & 1.5822 & 1.5698 & 1.5780 \\
PA-7 & 1.5941 & 1.5805 & 1.5895 \\
\hline
\end{tabular}

${ }^{\text {a }}$ Average refractive index; $n_{\mathrm{AV}}=\left(2 n_{\mathrm{TE}}+n_{\mathrm{TM}}\right) / 3$.

Table IV. Thermal properties of various polyamides

\begin{tabular}{|c|c|c|c|c|}
\hline \multirow{2}{*}{ Polymer } & \multirow{2}{*}{$T_{\mathrm{g}}\left({ }^{\circ} \mathrm{C}\right)^{\mathrm{a}}$} & \multicolumn{2}{|c|}{$T_{10}\left({ }^{\circ} \mathrm{C}\right)^{\mathrm{c}}$} & \multirow{2}{*}{ 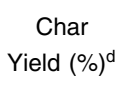 } \\
\hline & & In $N_{2}$ & In Air & \\
\hline PA-1 & $220(206)^{b}$ & $510(480)$ & 490 & 68.45 \\
\hline PA-2 & $160(160)$ & $410(385)$ & 395 & 46.35 \\
\hline PA-3 & $170(165)$ & 405 (380) & 390 & 42.30 \\
\hline PA-4 & $-^{e}(180)$ & $420(405)$ & 390 & 45.35 \\
\hline PA-5 & $180(165)$ & $400(380)$ & 390 & 44.85 \\
\hline PA-6 & $195(170)$ & $490(465)$ & 485 & 60.15 \\
\hline PA-7 & $220(210)$ & $500(480)$ & 485 & 65.70 \\
\hline
\end{tabular}

a Midpoint temperature of baseline shift on the DSC heating trace. ${ }^{b}$ Data in parentheses are the reported data of the sulfur containing analogous polyamides (see ref 30 ). ${ }^{\circ}$ Decomposition temperature at which a $10 \%$ weight loss was recorded by TGA. ${ }^{\mathrm{d}}$ Char yield calculated as the percentage of solid residue after heating from room temperature to

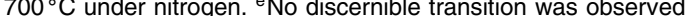

are summarized in Table IV. DSC was used to evaluate the thermal transition of polymers. All the polymers indicated no clear melting endotherms up to the decomposition temperatures on the DSC thermograms. These results also supported the amorphous nature of these polymers. Depending on the structure of the diacid component, chain flexibility, and steric hindrance of the polymer backbones, the $T_{\mathrm{g}}$ values of the polyamides were in the range of $160-220^{\circ} \mathrm{C}$. According to the results, PA-2, PA-3, and PA-5 containing less symmetric $m$-linked aromatic units and PA-6 with flexible ether groups had a lower $T_{\mathrm{g}}$ value due to the flexibility and low rotation barrier of their diacid moieties. Polyamide PA-1 and PA-7 exhibited the higher $T_{\mathrm{g}}$ because of the rigid aromatic units. In comparison with the related sulfur containing analogues polymers (Table IV), these polymers showed higher $T_{\mathrm{g}}$ that could be attributed to the less flexibility of $S=O$ group versus $S$ group in the repeat unit.

The thermostability of the polymers was examined by TGA measurements. The temperature of $10 \%$ weight loses $\left(T_{10}\right)$ in nitrogen and air atmospheres was determined from original termograms and are also tabulated in Table IV. The $T_{10}$ values stayed within the range of $390-490^{\circ} \mathrm{C}$ in air and within the range of $405-510^{\circ} \mathrm{C}$ in nitrogen. The char yields of all polymers at $700{ }^{\circ} \mathrm{C}$ in nitrogen ranged between $42-68 \%$.

\section{CONCLUSION}

In the present study, a new diether-diamine monomer containing sulfoxide and trifluoromethyl group was successfully prepared in high purity and good yields. Novel aromatic poly(sulfoxide ether amide)s PA-1-PA-7 were synthesized from this diamine monomer with various aromatic dicarboxylic acids via Yamasaki's phosphorylation method using triphenyl phosphite and pyridine. The polymers were amorphous in nature, readily soluble in common polar organic solvents, and showed high thermal stability and low refractive indices. The comparison of the results of thermal stability and solubility of prepared polymers with analogues sulfur containing polymers indicated that incorporation of $\mathrm{S}=\mathrm{O}$ into the polymer backbone effectively enhances the thermal stability and solubility of the rigid polymer backbone. These properties can make these polyamides attractive for practical applications such as processable high-temperature-resistance polymers because of noncoplanar $\mathrm{CF}_{3}$ and $\mathrm{S}=\mathrm{O}$ in the polymer chain.

Received: October 13, 2008 Accepted: November 18, 2008

Published: January 15, 2009

\section{REFERENCES}

1. P. E. Cassidy, “Thermally Stable Polymers," Dekker, New York, 1980.

2. H. H. Yang, "Aromatic High-Strength Fibers," Wiley, New York, 1986.

3. R. B. Seymour and C. E. Carraher, "Polymer Chemistry: An Introduction," Dekker, New York, 1981.

4. D. J. Liaw, W. H. Chen, and C. C. Huang, "Polyimide and Other High-Temperature Polymers," VSP, 2003.

5. S. Mehdipour-Ataei and H. Heidari, Macromol. Symp., 193, 159 (2003).

6. S. H. Hsiao and K. H. Lin, Polymer, 45, 7877 (2004).

7. C. Chiriac and J. K. Stille, Macromolecules, 10, 712 (1977).

8. K. A. Joseph and M. Srinivasan, Polym. Int., 32, 257 (2007).

9. R. R. Pal, P. S. Patil, M. M. Salunkhe, N. N. Maldar, and P. P. Wadgaonkar, Polym. Int., 54, 569 (2004).

10. L. Cheng and X. G. Jian, J. Appl. Polym. Sci., 92, 1516 (2004).

11. G. C. Eastmond, J. Paprotny, and R. S. Irwin, Macromolecules, 29, 1382 (1996).

12. F. Akutsu, M. Inoki, M. Sawano, Y. Kasashima, K. Naruchi, and M. Miura, Polymer, 39, 6093 (1998).

13. M. Kusama, T. Matsumoto, and T. Kurosaki, Macromolecules, 27, 1117 (1994). 
14. S. Itamura, M. Yamada, S. Tamura, T. Matsumoto, and T. Kurosaki, Macromolecules, 26, 3490 (1993).

15. G. Maglio, R. Palumba, and M. C. Vignola, Macromol. Chem. Phys., 196, 2775 (1995).

16. S. P. Patil, R. P. Ravindra, M. S. Manikrao, N. M. Noormahamad, and P. W. Prakash, Eur. Polym. J., 43, 5047 (2007).

17. D. J. Liaw, B. Y. Liaw, and M. Q. Jeng, Polymer, 39, 1597 (1998).

18. A. Shockravi, S. Mehdipour-Ataei, E. Abouzari-Lotf, and M. Zakeri, Eur. Polym. J., 43, 620 (2007).

19. H. R. Kricheldorf and A. Domschke, Macromolecules, 27, 1509 (1994).

20. S. H. Hsiao, C. P. Yang, C. Y. Tsai, and G. S. Liou, Eur. Polym. J., 40, 1081 (2004).

21. M. Nishida, K. Hosokawa, T. Ueda, and T. Aoki, J. Fluorine Chem., 43, 35 (1989).

22. D. J. Liaw, C. C. Huang, and W. H. Chen, Polymer, 47, 2337 (2006).
23. D. J. Liaw, W. H. Chen, C. K. Hu, K. R. Lee, and J. Y. Lai, Polymer, 48, 6571 (2007).

24. T. Oyama, K. Naka, and Y. Chujo, Macromolecules, 32, 5240 (1999).

25. A. Shockravi, S. Mallakpour, and F. Atabaki, Des. Monomers Polym., 11, 261 (2008).

26. A. Shockravi, S. Mehdipour-Ataei, E. Abouzari-Lotf, and A. Yousefi, Eur. Polym. J., 42, 133 (2006).

27. A. Shockravi, R. Alizadeh, H. Aghabozorg, A. Moghimi, E. Rostami, and S. B. Tabrizi, Phosphorus, Sulfur Silicon Relat Elem., 178, 2519 (2003).

28. W. S. Gump and J. C. Vitucci, J. Am. Chem. Soc., 67, 238 (1945).

29. N. Yamazaki, F. Higashi, and J. Kawabata, J. Polym. Sci., Part A: Polym. Chem., 12, 2149 (1974).

30. A. Shockravi, E. Abouzari-Lotf, and A. Javadi, Des. Monomers Polym., in press. 